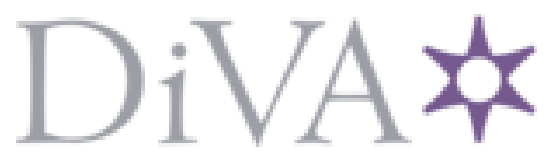

http://www.diva-portal.org

This is the published version of a paper published in Sport in Society: Cultures, Media, Politics, Commerce.

Citation for the original published paper (version of record):

Roe, D., Hugo, M., Larsson, H. (2019)

'Rings on the water': examining the pedagogical approach at a football program for detained youth in Sweden.

Sport in Society: Cultures, Media, Politics, Commerce, 22(6): 919-934

https://doi.org/10.1080/17430437.2019.1565381

Access to the published version may require subscription.

N.B. When citing this work, cite the original published paper.

(C) 2019 The Author(s). Published by Informa UK Limited, trading as Taylor \& Francis Group This is an Open Access article distributed under the terms of the Creative Commons Attribution-NonCommercial-NoDerivatives License (http://creativecommons.org/licenses/ by-nc-nd/4.o/), which permits non-commercial re-use, distribution, and reproduction in any medium, provided the original work is properly cited, and is not altered, transformed, or built upon in any way.

Permanent link to this version:

http://urn.kb.se/resolve?urn=urn:nbn:se:gih:diva-5719 


\section{‘Rings on the water': examining the pedagogical approach at a football program for detained youth in Sweden}

\section{Daniel Roe, Martin Hugo \& Håkan Larsson}

To cite this article: Daniel Roe, Martin Hugo \& Håkan Larsson (2019) 'Rings on the water': examining the pedagogical approach at a football program for detained youth in Sweden, Sport in Society, 22:6, 919-934, DOI: 10.1080/17430437.2019.1565381

To link to this article: https://doi.org/10.1080/17430437.2019.1565381

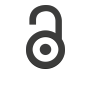

(c) 2019 The Author(s). Published by Informa

UK Limited, trading as Taylor \& Francis Group

Published online: 06 Feb 2019.

Submit your article to this journal $\square$

Џ Article views: 196

View Crossmark data $₫$ 


\title{
'Rings on the water': examining the pedagogical approach at a football program for detained youth in Sweden
}

\author{
Daniel Roe ${ }^{a}$, Martin Hugo ${ }^{b}$ and Håkan Larsson ${ }^{a}$ \\ aSwedish School of Sport and Health Sciences, Stockholm, Sweden; 'bschool of Education and Communication, \\ Jönköping University, Jönköping, Sweden
}

\begin{abstract}
Studies indicate that sport within youth institutional settings can be beneficial (e.g. learning social skills) or problematic (e.g. social exclusion) depending on how they are structured, delivered and, ultimately, experienced by students. In this article, we examine the experiences of students and staff in an educational sport program at a Swedish all-male youth detention home (ages 16-20) in order to increase understanding of the pedagogical approach of a sports-based program for detained youth. Drawing on interviews with both students and staff, we identify and elaborate four aspects of the program-building a pedagogical platform,'seeing' and meeting students, creating a supportive environment, and thinking beyond the institution - that were collectively represented to initiate and guide a process of growth and change for students. We discuss how these aspects of the program's pedagogical approach, in contrast to deficiency-based approaches, can provide a useful framework for delivering sport in ways that can benefit detained youth and other young people in socially vulnerable situations.
\end{abstract}

\section{KEYWORDS}

Sport pedagogy; youth justice; pedagogical tact; football; Sweden; detained youth

\section{Introduction}

Sport can play an important role in the rehabilitation and reintegration of detained youth. Studies show that sport within youth institutional settings can be beneficial or problematic depending on how it is structured, delivered and, ultimately, experienced by young people (Andrews and Andrews 2003; Meek 2014; Parker, Meek, and Lewis 2014). In order for sport to have an impact on wider social outcomes such as crime desistance or developing prosocial skills, research indicates that specific pedagogical approaches and competencies are needed (see Haudenhuyse, Theeboom, and Skille 2014). This is consistent with broader research on sport and social development, which indicates that sport participation can contribute to social development if the activities are structured specifically with this aim in mind (Bailey et al. 2009). Additional research on sport pedagogy in youth justice settings is needed in order to understand how detained youth experience sport and how sport can be arranged in ways that are meaningful and beneficial for them.

The purpose of this article is to increase the understanding of the pedagogical approach of a sports-based program for detained youth. We do this by exploring the experiences of 
students and staff in an educational football program at an all-male youth detention home in Sweden. The research questions were:

- What are the experiences of students and staff in the Football Program?

- What are the characteristics of the pedagogical approach implemented in this program?

\section{The potential for sport in correctional settings}

A growing body of mainly interventional research has drawn attention to the potential benefits of sport within various criminal justice settings for young adults and juvenilesincluding youth prisons (Meek and Lewis 2014), closed institutions for juveniles (Andrews and Andrews 2003), and probation or re-entry programs (Van Hout and Phelan 2014). Such benefits include formation of prosocial identities; socio-emotional development; coping with boredom and other negative aspects of institutionalisation; improving relations between residents and personnel; and, more generally, a structured alternative to criminal or risky behaviour (Andrews and Andrews 2003; Meek 2012, 2014; Meek and Lewis 2014; Nichols 2007; Parker, Meek, and Lewis 2014; Van Hout and Phelan 2014; Williams, Strean, and Bengoechea 2002). This body of research tends to focus on 'outcomes', where sport in an almost evangelical sense (Coalter 2013) is taken to have nearly intrinsic properties that are instrumental in creating the desired outcomes.

Sport's contribution to rehabilitating detained youth is often framed as initiating a developmental process, starting with a 'hook' for motivating 'hard-to-engage' youth-particularly males (Meek 2014; Meek and Lewis 2014; Nichols 2007). Secondly, research highlights that sport can provide a context in which detained youth are able to develop socially and emotionally, and build self-confidence and optimism for a better future-one that may include crime desistance (Parker et al. 2014). Lastly, studies show that sport can play a supportive role for reintegrating young people during community re-entry (Meek 2014; Meek and Lewis 2014).

Sport is not a panacea, however. According to Spruit et al. (2016), 'there is no overall significant association between sports participation and juvenile delinquency' (655). In fact, several studies point to detrimental outcomes related to sport in correctional settings, such as bullying or other forms of social exclusion (Andrews and Andrews 2003; Meek 2014). In scholarship on prison masculinities, sporting contexts have been depicted as sites wherein exaggerated masculinities linked to competition and violence are performed and reinforced (Abrams and Anderson-Nathe 2013; Baumer and Meek 2018). Academics (Andrews and Andrews 2003; Sugden and Yiannakis 1982) have also questioned the use of competitive, mainstream sport models because they constitute elements of society, such as adhering to formal rules, with which delinquent youth already struggle.

Still, a few studies (Meek 2012, 2014; Meek and Lewis 2014) concerning football and rugby academies at British young offender institutions show that mainstream sports hold promise for reducing reoffending. However, echoing research in physical education (see Bailey et al. 2009) and community sport (see Mahoney and Stattin 2000) these studies tribute desirable outcomes to pedagogical aspects and program structure, such as the guidance provided in mentoring relationships, rather than the activity itself. Thus, an important focus for future research is not so much if sport interventions can benefit the situations of 
detained youth, but rather to understand the complexities of how sport can be arranged and delivered in ways that benefit detained youth (Meek and Lewis 2014).

\section{Conceptualising sport in youth justice contexts-a pedagogical practice?}

The framework for this study is that the potential benefits (or consequences) of sport within youth justice contexts can be understood in relation to its pedagogical practice, that is, how sport is conceived, how it is delivered, and how it is experienced by young people. Furthermore, our approach is that the notion of rehabilitation through sport should not be understood reductively or instrumentally, as if following a step-for-step process in a manual, but as occurring within an interpersonal dimension - through the relations and day-to-day interactions among residents and staff (Abrams and Anderson-Nathe 2013; Hertting 2010; Jenner 2004). This interpersonal dimension is profoundly influenced by intersecting discourses regarding how detained youth are perceived, how institutions interpret their mission and put it into practice and, within such perspectives, how the role of sport is conceived. As Meek (2014) suggests, sport can be conceptualized as a practice negotiated within the 'contrasting notions of punishment, containment, and rehabilitation'. In closed institutions, the provision of sport is largely dependent on the institution's conduct-its regimes, history, and culture (Meek 2014; Norman 2015).

Although in theory, and relative to adult corrections, institutions of youth justice have a rehabilitative mission, scholars (Case and Haines 2015; Muncie 2008) contend that European youth justice can increasingly be characterised by elements of control and correctionalism (i.e. seeking to correct or even punish youth crime 'as the outcome of deficiencies in the individual'). In regards to physical activity, a frequently discussed example of correctionalism is the boot camp approach - where youth are subjected to strenuous physical demands and even 'planned and repeated humiliation' in a military structure (Cullen, Blevins, Trager, and Gendreau 2005). Although boot camps aimed to instil self-discipline in youth, Kilgore and Meade (2004) show how students hardly learned responsibility because it was taught (imposed upon them) in a way that did not permit students to practice it themselves.

A parallel 'deficiency' discourse could be pointed out in community sport (Coalter 2013), in which sport-based programs target groups of individuals who are seen as at-risk, marginalised or otherwise problematic and, accordingly, require an intervention: being corrected, integrated, or otherwise diverted from creating problems (Ekholm 2016; Kelly 2013). In a sense, such interventions could be seen as 'correctional settings' in their own right.

A body of Swedish research articulates an alternative approach, advocating that youth detention homes can be conceptualised as 'pedagogical practices' (Fritzén 2001; Gerrevall and Jenner 2001; Hugo 2013; Jenner 2004). This approach involves adopting a 'pedagogical perspective' that focuses partly on students' development of knowledge and skills, and partly on their integration into a shared community (Fritzén 2001). It is characterised by trying to see detained youth as being situated in problematic life situations, rather than individuals who are problematic (Gerrevall and Jenner 2001). In this sense, the pedagogical mission for youth homes is to construct a learning environment that is adaptable and capable of meeting the complex and varying needs and interests of detained youth in relation to being able to integrate within the community (both at the youth home, and in society at large). Jenner (2004) elaborates that the task for practitioners, then, is to adopt a 'life world' 
perspective, that is, to develop an attitude and ability 'to transcend one's own perspective and, as far as possible, see the world through the eyes of the pupil' (12).

Acknowledging the unique, indeed difficult character of this 'pedagogical task', Hugo (2013) finds that many students in Swedish youth detention homes in fact experience being met in a respectful way, often leading to positive progress in school. Hugo concludes that in order to facilitate meaningful learning experiences in this setting, a critical teaching competence for meeting these students is 'an ability to quickly feel what is possible and meaningful in the situation and meet students precisely where they are' (131). This ability can be likened to what van Manen (2015) calls pedagogical tact. Pedagogical tact can be described as an interpersonal competence wherein the teacher can interpret what the student feels within the varying and dynamic situations of the student-teacher relation. It involves orienting to students' lived experiences (van Manen 2015) — to meet students' curiosity, wants, and needs by reading their physical being and understanding what is meaningful for them in the concrete moment (Hugo 2013).

\section{The Football Program}

The site for the study, a youth detention home in southern Sweden, was selected because it has a stated sport profile, with a focus on football (henceforth the 'Football Program'). The institution houses 31 males between ages 16 and 20 in either locked or open units. The youth (students) placed at the institution are described as having 'severe psychosocial problems with ongoing criminality and drug abuse. Table 1 provides a general overview of residents' background in terms of substance abuse, criminality, schooling, and peers/leisure.

The institution is situated on an island with about 750 inhabitants, where the youth detention home is the largest employer. The island's local sport club also has a relatively strong position in the community and organizes a variety of sports and recreational activities, including competitive football. For decades, the institution and the sport club have collaborated, where both students and staff at the institution have been members and played football together. This tradition was an inspiration to create the Football Program, which formalises a partnership between the institution and the club.

The Football Program aims to 'help students develop lasting prosocial skills and leisure interests', which can be contextualised within the institution's general treatment philosophy emphasising leisure activities and individual relationship work. The delivery of the program, however, is not guided by any clear or explicit pedagogical model. Football plays a central part in the institution's culture and provided a way for a variety of professionals to

Table 1. Characteristics of residents placed at the institution regarding substance abuse/ addiction, criminality, school, and peers/leisure.

\begin{tabular}{lll}
\hline $\begin{array}{c}\text { Substance } \\
\text { abuse }\end{array}$ & - & Abuse including alcohol (95\%) \\
Criminality & Repeat use of multiple substances (65\%) \\
& - Criminal record (100\%)_compared to 62\% at all state-run youth institutions \\
School & - Heavy addiction combined with violent crime (65\%) \\
& - & Leed extra support in school (89\%) \\
Peers and & - Need support with respect to peers (88\%) \\
leisure & - Lack leisure interest at admission (80\%) \\
\hline
\end{tabular}

Data provided by the institution and social services. 
collaborate, often informally and without specific guidelines. These professionals include treatment assistants (unit staff), the psychologist and nurse, administrators, and even groundskeepers. It also involves outsiders, besides the local sport club, in the form of representatives of the Swedish Football Association (including a former national team coach who volunteers with the program) and the regional sport federation, who regularly visit the youth home to engage in the program. These outsiders also assist the program with an informal network for connecting students to sport clubs during their re-entry.

The Football Program consists of three main activities: physical education (PE) with a special focus on football at the institution's onsite school (delivered primarily by the PE teacher), recreational football during evenings (delivered by unit staff), and competitive club football (delivered by the local sport club). In Sweden, all competitive sport below the elite level is a leisure time activity, meaning that club coaches are normally not professional or full-time coaches. One important feature of this program is that the head coach of the football club works as a treatment assistant at the youth home. Another key aspect of the Football Program is that participation in all activities is essentially voluntary, including during school as most of the students are not compulsory school age. Students for the most part can choose how much they participate, with the exception of club football, where students at the institution must be invited to play.

$\mathrm{PE}$ at the Football Program is split into morning and afternoon sessions, during which morning lessons are typically held in a classroom, while afternoon sessions consist of physical activities, most often football. Football sessions during school are mainly conducted in smaller groups (up to five students) or one-on-one with the PE teacher, where the students train various skills and play small games. Recreationally, students and staff play pick-up football together during most evenings when, depending on interest, there can be up to 20 participants (including staff). Compared to these sessions, participation in the club is more structured and selective. In this part of the program, students who are assessed as having sufficient behaviour and football ability are invited to train and even play games with a men's Division 5 football team (typically between three to six students at any one time).

\section{Method}

This study is inspired by a life world phenomenological approach (Bengtsson 2005; Hugo 2013; van Manen 1990; 2016), in which the researcher seeks to enter and participate in the social world of the subjects-by meeting and interacting with the people she/he is researching in everyday situations - in order to come to a closer understanding of their unique worlds of lived experiences. Participation in activities was thereby a deliberate part of the ethical-methodological approach conducive to minimising the distance between researcher and subjects, helping to interpret and describe the data, and encouraging positive experiences for research participants.

\section{Selection and data collection}

The data was collected during a one-week visit to the institution in the spring of 2015, using semi-structured life world interviews (Brinkmann and Kvale 2015). This method allowed follow-up questions based on how the participants responded, as well as posing questions regarding what the researcher observed and experienced in the social environment 
(Brinkmann and Kvale 2015). Several qualitative studies with detained or court-involved young people (Abrams and Anderson-Nathe 2013; Van Hout and Phelan 2014) have discussed the importance of building trust and familiarity with participants prior to interviews. In this study, the first author participated in two football trainings (one with the club team and one PE lesson), allowing him to interact with the students and to explain the purpose of the research in a mutually familiar setting prior to the interviews.

Regarding selection, since we understand pedagogy to be co-constructed within interactions between educators and students (van Manen 2015), representatives of both were interviewed. We categorize the participants (see Table 2) as students, educators (those who more directly interacted with students) and other staff (those who could add perspective on how the program was structured and delivered). Various staff were selected based on their involvement in the school and club parts of the program. All student names are pseudonyms.

The students selected for this study were the boys who participated with the club team $(n=5)$. This included one student (Oliver) who went to several trainings at the club but ceased his participation, seeming to prefer recreational football instead. Students had different backgrounds in sport. Only one student (Adam) had extensive experience with organized club sport (hockey). Oliver, who had a background in parkour, had not played much football or other team sports previously. The other students (Karim, Jamal, and Samir) had principally played recreational football with friends, with some short-lived involvement in organized sport (Karim with mixed martial arts and Jamal with football).

Interviews with students centred on previous sport experiences, experiences at the Football Program, and future expectations. Students were asked, for example, to describe their life at the institution and their participation in the program; could the program be changed or improved in any way? Interviews with practitioners focused on the role of sport at the institution, and, particularly for the educators, more in-depth explanations regarding how sport was delivered, for example to describe the aims and procedures of their methods/ strategies. All interviews were digitally recorded with the permission of participants, and staff members consented to the use of their professional title in the research.

\section{Interpretation of the data}

The findings represented in this article are the result of a continuous hermeneutical interpretation (van Manen 1990, 2016). An initial interpretation of the data was conducted in the spring of 2015, during which the interview data were transcribed, re-read, coded, and grouped into themes. Subsequently, the first author conducted two follow-up visits in the summer and fall of 2015 during which he participated more extensively in sport activities

Table 2. Study participants and length of interviews.

\begin{tabular}{lll}
\hline Students $^{\mathrm{a}}$ & Educators & Other staff \\
\hline Adam $(52 \mathrm{~min})$ & PE teacher $(64 \mathrm{~min})$ & Institution's director $(66 \mathrm{~min})$ \\
Jamal $(20 \mathrm{~min})$ & Coach $(47 \mathrm{~min})$ & Director of programming $(50 \mathrm{~min})$ \\
Samir $(16 \mathrm{~min})$ & Former national team coach $^{\mathrm{b}}(22 \mathrm{~min})$ & Administrator $/$ club team chairman $(51 \mathrm{~min})$ \\
Karim $(25 \mathrm{~min})$ & & Psychologist $(32 \mathrm{~min})$ \\
Oliver $(13 \mathrm{~min})$ & & \\
\hline
\end{tabular}

${ }^{\text {aAll }}$ names are pseudonyms.

bolunteer at the program 
at the Football Program. During these visits, the first author, who has previous teaching experience in youth justice contexts in the United States, experienced an approach that was comparatively refreshing, forward-thinking, and enjoyable. While these observations are not used empirically in this paper, they have been helpful for interpreting the data by posing follow-up questions during a continuous hermeneutical interpretation (van Manen 1990, 2016). In what ways did the students experience this approach? What is the pedagogical significance of their experiences?

In presenting our interpretation of the data, we seek to provide a close description (Bengtsson 2005), meaning that the interpretation is expressed as much as possible in the terms of the interviews. In the findings, empirical examples are presented in a dialogical fashion between the various participants to reflect the co-constructive, interactive nature of pedagogy. Van Manen (2015) describes 'reversibility' in pedagogy. For example, while it is important for teachers to 'see' pupils it is likewise important for pupils to experience 'being seen'. The students' descriptions in this study can thereby corroborate and give meaning to the methods, strategies, and contextual aspects described by the staff.

\section{Ethical considerations}

The research followed the Swedish Research Council's (2002) four major requirements for social research: informing participants about the study, obtaining voluntary consent, maintaining the confidentiality of participants, and using research for strictly scientific purposes. In addition to these requirements, the research also followed specific ethical guidelines from the Swedish Institutional Care Board (Statens institutionsstyrelse 2014). These guidelines are stipulated in recognition of the nature of compulsory care and the vulnerable situation(s) of youth placed in detention. A central consideration of the research was therefore to be mindful of the relative position of power and forms of (albeit unknowingly) coercing participation. The first author was required to review these institutional guidelines and to sign a confidentiality agreement. Furthermore, following the recommendation of Swartz (2011), the research sought to exceed ethical expectations in that students should enjoy their participation. At the end of an interview, one of the students, Adam, commented:

When guys like you come here, at first we are like, who's that? Who's that? He's new here, we don't like outsiders like that. But then, alright, he's here to talk with some of us and, yeah, he's going to ask questions. There's nothing wrong with that. As long as we can help. And it's cool if you can take it with you back to the US... Yea, if you can do that, get the opportunity to do that, it would be really cool I think. And everyone here would think that, too. Because then we helped.

\section{Findings}

Early on in the project the first author noted that most of the students described positive experiences at the Football Program from which they felt better, physically and mentally. Moreover, in the main the students described their experiences in the program as 'fun' or enjoyable, for example in Oliver's quotation below:

I didn't like football at all before I came here, but when I came here I really liked it. You got to try it, and it was fun, and you wanted to do it more and more. 
Like Oliver, the other students interviewed in this study described their experiences at the Football Program in sequences, in reference to a process of growth, change, and/or (re)discovering an interest for sport. Also, like in Oliver's statement, the students' engagement in the program could be related to voluntarily experiencing an enjoyable or 'fun' environment at the Football Program. Minding these characteristics of the interviews, we have constructed and ordered the findings around four themes: building a pedagogical platform, 'seeing' and meeting students, creating a supportive environment, and thinking beyond the institution.

\section{Building a pedagogical platform}

Sport, and specifically football, was described as a popular, shared interest among both students and staff. Adam remarked, 'It's always football we're talking about every day. If you don't talk about football, something is really wrong!' This common interest was represented as an important part of a 'pedagogic platform' in which staff and students could relate to one another, build trusting relationships, and help empower youth to get 'a new start in life'. In this way, by recognizing football as a mutual interest for students and staff, football could become a platform for a pedagogical process: building relationships and teaching youth about 'other things than just soccer'. Adam described these 'other things' in terms of developing social skills:

It's so much more than just playing. It's getting social skills that I can use when I'm moving to my own place. Yeah, I think it's important to... look at the whole thing in another view. So at first I just thought we're just playing and... it has nothing to do with social skills. But now when I've been here for [a long time] it's almost not playing, it's just social skills training.

Several staff cautioned that, in the context of youth institutional care, the potential of sport as something 'more than just playing' could be overlooked. Similarly, the director of programming expressed that in being 'too serious', other institutions failed to see pedagogical potential in sport:

I think that a lot of institutions are a little bit too serious and consider this [program] as not serious. And that's wrong... When people talk about football, they say it's like, you know, kicking around but nothing else. And they don't see all the other things.

In the case of this program, sport as a 'pedagogical platform' means neither to underestimate the potential of sport as a developmental context (i.e. 'kicking around but nothing else') nor to overestimate it (i.e. seeing sport as a panacea for rehabilitation). Here, sport-football-was seen as an opportunity for a pedagogical practice, a social context where students and staff could meet and learn from one another in meaningful interpersonal relations. In this particular case, however, the pedagogical perceptibility of sport at the institution could be largely attributed to its history of collaboration with the sport club.

\section{'Seeing' and meeting students}

Both students and staff described how engagement in the program was related, in part, to respectful pedagogical meetings without coercion-ones where students were understood and valued by staff. These relations, perhaps as much as their enjoyment of the actual 
football playing, were important for the students' continued involvement. One of the students, Samir, described how his experience of being 'seen' and not being 'forced' was important for his engagement in the Football Program:

You should never, you know, make someone, like, play football, not force someone to become better if I don't want to become better... That's the most important. [The PE teacher] doesn't do it. You know, if he sees that you don't want to, if we are tired or something, he doesn't nag or anything, he says that we take it easy today. That's really good, he like checks with us; he doesn't want it to be tough for us to be there. It's always fun to be with him then; that also makes us always want to be in class and to learn, too. Then you think it's fun. That's a good thing that I think teachers should have.

Samir's recommendation describes a pedagogy in which the teacher sees the student and is able to motivate him without 'forcing' him. In other words, 'having fun' and 'wanting to be there' were dependent on the teacher's ability to meet the student without being coercive or directive. The PE teacher elaborated how such a dynamic ability to meet students, even under difficult circumstances, could create learning moments:

Some days you have to throw away all the books that you have because they have had a bad night, maybe they have had a talk with their parents the day before, maybe they are going to have a meeting with the social service in the afternoon; it's a lot of things going through their mind. Then I think that that day you should just sit down and drink coffee and talk some shit.

Having an ability to meet the needs and interests of students occurred within, and were enabled by, close and trusting relationships between students and staff. Adam, for example, described how relations with the PE teacher and coach allowed them to 'teach us in a whole other way':

He's not just the teacher, or someone who is working here. You get to know someone and you obviously get to teach us in a whole other way. You see us from our best side when we play football because everyone loves and enjoys playing football so much they don't think about anything else.

For Adam, this sport context, perhaps more so than other parts of institutional life, is a place where he can be seen and recognized in a positive light: from his 'best side'. Such pedagogical meetings enabled students to transport themselves into a type of new 'arena' for developing success, helping them move out of their unsuccessful pasts or situations where they might be seen as problematic.

Like Adam, most of the students reported having 'respectful' relationships with educators at the Football Program.

Jamal: I have a good contact. Respect, it's about respect. We joke with each other. It's a good contact actually.

Interviewer: Why do you have respect for them?

Jamal: Because they have respect for me, and then I give them respect back. It's all about respect.

Similar to Jamal's description, the students depicted how empathetic qualities such as 'listening' and 'understanding' were what made a good coach or teacher:

[The PE teacher] is not like stone hard. I don't know the right word for it, but some coaches just scream at you, and some coaches are more like understanding and encouraging. [The PE teacher] is like that. He encourages you. That's a good coach. (Oliver) 
The PE teacher similarly described how a certain disposition for listening, understanding, and being non-judgmental formed the 'foundation' for building a relationship:

The guys can talk with me and feel safe that I listen and I don't impose my values on them. We can discuss. I can think that maybe it was wrong of them, but I don't get angry with them...

They've already had a lecture. That's a lot of the foundation when you build a relationship.

Respondents also discussed the importance of 'wanting the best' or genuinely caring for students.

It's that [the PE teacher] wants us to train. He wants the best for us. (Karim)

You have to want to see young people grow and help them, yea, like a little prospect, almost like parenting in some ways. (Director of programming)

These statements convey how learning at the Football Program was experienced in terms of an interpersonal dimension. In other words, the Football Program served as a platform where mutually agreeable and voluntary pedagogical meetings could take place; meetings which students often perceived to be in their best interest. What seemed to facilitate these relations was a certain disposition to 'see' the students, and a dynamic ability to make such meetings meaningful for the individual students.

\section{Creating a supportive environment}

The students described their interest in the program in reference to a certain social environment, one that motivated or even 'challenged' them to learn. This environment was characterised in terms of being 'fun', 'welcoming', and 'safe'. Often, the social environment at the Football Program was contrasted with other aspects of institutional life, particularly confinement in the wards. Three of the students described how football and other exercise offered relief from 'strains' and boredom. Samir, for example, described how sport alleviated the feeling of being confined:

It's like your body itches, you can't sit still, you know. So when you play football or do sports you're a little bit calmer... You can also, like, clean your thoughts.

When asked what he liked best about sport and PE, Jamal said:

It's about football. When we're going to play football, we don't go to fight. We go to play football.

In these ways, four of the students described PE and football as a sort of free zone in relation to what could be a stressful, even hostile social environment at the institution. In this sporting context, the social tensions between people that add to the stresses of institutional life could be dissipated. This point was not taken for granted by the PE teacher, who expressed how creating a 'fun' learning environment together with the students supported them to 'learn without knowing':

We should have a nice day together... And if we make it fun together they come back every day and they learn without knowing that they're learning.

The notion of 'learning without knowing' reflects how the program set about motivating students by inviting them to participate in a mutually enjoyable context. A concrete example 
of this can be seen in how the Football Program addressed a problematic gym culture by removing the weight room at the institution. The PE teacher explained:

Students get so fixated with muscles and they compare with each other... That I don't want to have because that builds a stress for them... Then we get the problem with steroids... and many of them have been doing steroids before. That's why I believe in this functional training... Because then you take away this, that you train not to get big muscles, you train because you want to feel good. And something that I've noticed is if two guys start with it one week, then it's four that trains next week, so it becomes rings on the water. You just need to crack this gym code, the weights. It exists other ways to train.

In this instance, cracking the 'gym code' could be accomplished by creating a different exercise culture. Significantly, the approach to engaging the students emanates from a caring concern-wanting to replace 'stressful' sport experiences with ostensibly beneficial ones, where exercising for well-being and enjoyment was emphasised. The PE teacher then uses the expression 'rings on the water' (the Swedish term for ripple effect) to describe how students would voluntarily take part in 'other ways' of training. Of note, then, is Oliver's statement of what he learned in the program: 'It doesn't have to be about winning. It can be about having fun.'

In this way, an inviting atmosphere that de-emphasised competition, particularly with the PE teacher, was represented to encourage students to develop a prosocial interest in sport. While the school formed the part of the Football Program where students could work on their football skills in a fun, 'secure' way, without the stress of performance; the club was where students could play 'real' (competitive) football. This authenticity, training and playing matches with others who were not residents at the youth home, seemed to form an important aspect of the project. The club was framed as a 'real' world 'social arena' where students could practice, or 'test', the skills, attitudes and interests deemed important for life on the outside. Three students described learning social skills by meeting other people at the club.

To care about other people. Think about my surroundings, those who exist around me, actually, because that's what you do within sports, especially team sports. You think about your teammates. (Samir)

Staff appreciated that 'daring' to integrate with a new social group could be a challenging task for students. And although some of the staff perceived that there were certain risks for students participating in the club, they represented that these could be mitigated in a 'welcoming' environment.

Interviewer: I noticed one thing, you called them out, the students from here, in front of everyone else.

Coach: I think it's time for them to grow. Of course, I can sink them. But then I talk to them. I talk to them after the training. I talk to them here (at the institution).

Here, the coach describes a tension wherein staff should prevent youth from re-experiencing failure while at the same time pushing them to 'grow'. The coach understands how potentially detrimental effects of criticizing or calling out students could be mitigated through dialogue and close relations. Adam described the rewarding experience of being challenged:

If you push someone that's a little bit insecure in themselves it's like... he learns that he can do that. He learns that I can do that and it makes you feel so good. 
The psychologist explained how a fear of stigmatization often caused students to 'distance' themselves from 'normal' adults and peers outside of the institution. At the sport club, however, he reported how students said they 'can meet [others] and they say that we are not so different. We can be friends. We can blend in.' Adam described the importance of 'belonging' at the club:

They're letting us play from [the institution] in [the club team] and I think that's cool because then you feel you belong somewhere. And that's kind of important for us who live here.

\section{Thinking beyond the institution}

This program helps us think that we can go so far, we can do all kinds of stuff, and those thoughts is very important for us. (Adam)

This quote by Adam illustrates how the Football Program was represented to help expand students' horizons of possibility, and broaden their perspectives on life. Their involvement played a part in helping them 'come back to life' (Karim) from extremely vulnerable and chaotic life situations where '[some of us] have destroyed ourselves in a way people cannot imagine' (Adam). Significantly, all of the students were hopeful for their futures, and described an interest to continue with sport in terms of balance with other parts of life.

In 5 years maybe I can become a player, train a lot, and maybe you can become something. But I'm also going to work and earn money, have my own apartment, and take care of myself. If I'm off on my free time, I'm not going to watch TV. I'm going to play football. (Jamal)

While this optimism is encouraging, in Jamal's statement we can also see the potential challenges of youth re-entry: securing housing and living independently, finding work, and 'training a lot', all while continuing to develop as young adults. The students' future expectations raise questions about how students will experience sport when they leave institutional care, and how such plans might be supported in their immediate and long-term futures.

Looking beyond re-entry, several respondents described how sport experiences could be drawn upon later in life, even in the event of a relapse.

In some ways, sport is going to stay connected with me. Even if I don't play, it can be a friend who plays, it can be my own kids if I have some, I can just be going to watch some game. I'm always going to enjoy sports no matter how old I get. (Adam)

It's something that they can use when they are 25 . Even if they get a relapse, when they are 25 they can think about: 'I did this and I know how I'm going to do it. And I can do it again.' (Director of programming)

These statements by Adam and the director of programming, who spoke from her experience as a mentor for a former student, indicate a latent value of creating positive sport experiences that may extend beyond measured outcomes, such as recidivism.

\section{Discussion}

The purpose of this article was to increase the understanding of the pedagogical approach of a sports-based program for detained youth by way of exploring the experiences of students 
and staff in an educational football program at an all-male youth detention home. This is important also because the program is delivered without having any explicit pedagogical model to guide it, but rather is pursued based on what the staff/educators 'feel' is right for the boys.

The students in this study reported several benefits of sport participation, consistent with previous research in the field. In the immediate term, their engagement in the Football Program helped them feel better, mentally and physically, and relieved some of the negative aspects of institutionalisation (Meek and Lewis 2014; Parker et al. 2014). Moreover, students in this study reported (re)discovering an interest in sport (Van Hout and Phelan 2014), improving social skills and emotional control (Meek 2012, 2014), and gaining optimism for their futures (Parker et al. 2014). In a broader sense, the students' experiences in the Football Program seemed to expand their life perspectives and horizons of possibility. Such developments can support youth in their re-entry (Parker et al. 2014) and may constitute a shift towards crime desistance (Van Hout and Phelan 2014).

Two important limitations to this study, however, are the selection of the students and the possibility of reporting socially desirable responses. It is paramount to acknowledge that the positive experiences of the students interviewed in this study might be partly attributed to them being a specifically selected group who exhibited both an aptitude to follow the rules at the institution and an 'ability to play' (see Dukic, McDonald, and Spaaij 2017).

The second research question was concerned with understanding the characteristics of the pedagogical approach implemented at the Football Program. In the findings section we indicate the notion of 'rings on the water', where participation in the program contributed to experiences of positive personal development among the students, as in significant ways guided by a tact of teaching (van Manen 2015) where practitioners brought sport to life in ways that were fun and welcoming. Our interpretation is that the themes that structured the findings section above-building a pedagogical platform, 'seeing' and meeting students, creating a supportive environment, and thinking beyond the institution-constitute a type of enacted pedagogical model, although no such model has been formulated explicitly. This 'rings on the water' approach seemed to invite the students to participate, as opposed to directing or coercing, in large part due to the educators' dispositions for understanding students and their abilities to make students feel respected and valued. Such dispositions and dynamism for meeting students resembles what van Manen (2015) describes as 'improvisational preparedness'. Sport research from abroad has similarly highlighted the importance of a 'perceptivity' towards the life situations of young people (see Haudenhuyse, Theeboom, and Coalter 2012) and a non-coercive or 'emancipatory' style of delivery (see Kelly 2013; Haudenhuyse et al. 2014).

Students' engagement also seemed to be related to a collaborative effort by actors both at the institution and in the sport community to create a supportive environment. Here, we must acknowledge that youth justice practitioners have the difficult task of challenging students to grow while also ensuring that they do not (re)experience demoralising failure (Hugo 2013). This study suggests how cultivating a supportive environment can give educators room to safely challenge detained youth and provide opportunities for them to experience success while also minimizing risks for failure.

Nevertheless, the findings show that (in this context) it seems important to avoid exaggerating the instrumental side of sport participation, and instead, to emphasize playing 
sport for its own sake as an experience that is 'for real' (see Hugo 2013). Arguably, if students were to perceive that sport and pedagogy were used to discipline them, as in a method for social control, then they might develop ways of resisting participation in the program (see Norman 2015). It is important to note that the students in this study described authentic experiences of both pedagogical relations and playing football in the club team.

Another key aspect of the program was having perspective beyond the institution. Upon release, detained youth are asked to re-integrate into communities where most were never meaningfully integrated to begin with, while simultaneously continuing to develop as young adults (Fader 2008). It would be naïve to think that sport-based programs operating strictly within institutions could resolve the myriad of structural and personal constraints (see Collins and Kay 2014) related to these young peoples' social exclusion. Therefore, similar to other studies on sport in youth corrections (Meek 2014; Parker et al. 2014), we stress the importance of providing 'through-the-gate' and long-term support. However, further study is warranted for understanding how sport can be arranged to support formerly-detained youth in community settings.

\section{Conclusion}

The themes described in this study indicate how certain pedagogical aspects of the Football Program were represented to initiate and guide a process of growth and change for a select group of detained youth. Our intention, however, is not to prescribe a model for 'best practice' when delivering sport in youth justice contexts. We caution against an instrumental approach where pedagogy is understood narrowly as a technology for correcting or including youth (see e.g. Ekholm and Dahlstedt 2017). We recommend that institutions take an approach where sport is (re)conceptualised as part of a pedagogical practice-a developmental environment that endeavours to expand young peoples' horizons and life perspectives. In contrast to deficiency-based approaches within both youth justice and community sport, developing dispositions and abilities to meet students in meaningful interpersonal relations can provide a useful framework for delivering sport in ways that can benefit youth in detention and other socially vulnerable situations.

\section{Disclosure statement}

No potential conflict of interest was reported by the authors.

\section{References}

Abrams, L. S., and B. Anderson-Nathe. 2013. Compassionate Confinement: A Year in the Life of Unit C. New Brunswick, Canada: Rutgers University Press.

Andrews, J. P., and G. J. Andrews. 2003. "Life in a Secure Unit: The Rehabilitation of Young People through the Use of Sport." Social Science \& Medicine (1982) 56 (3): 531-550.

Bailey, R., K. Armour, D. Kirk, M. Jess, I. Pickup, R. Sandford; and BERA Physical Education and Sport Pedagogy Special Interest Group. 2009. “The Educational Benefits Claimed for Physical Education and School Sport: An Academic Review." Research Papers in Education 24 (1): 1-27.

Bengtsson, J., ed. 2005. Med Livsvärlden Som Grund: Bidrag till Utvecklandet av en Livsvärldsfenomenologisk Ansats i Pedagogisk Forskning. Lund, Sweden: Studentlitteratur.

Brinkmann, S., and S. Kvale. 2015. InterViews: Learning the Craft of Qualitative Research Interviewing. London, UK: Sage. 
Baumer, H., and R. Meek. 2018. “Sporting Masculinities in Prison.” In New Perspectives on Prison Masculinities, edited by M. Maycock and K. Hunt, 197-221. Basingstoke, UK: Palgrave MacMillan.

Case, S., and K. Haines. 2015. "Children First, Offenders Second: The Centrality of Engagement in Positive Youth Justice." The Howard Journal of Criminal Justice 54 (2): 157-175. doi:10.1111/ hojo.12099.

Coalter, F. 2013. Sport for Development: What Game are We Playing? London, UK: Routledge.

Collins, M., and T. Kay, eds. 2014. Sport and Social Exclusion. New York, NY: Routledge.

Cullen, F. T., R. K. Blevins, J. S. Trager, and P. Gendreau. 2005. “The Rise and Fall of Boot Camps." Journal of Offender Rehabilitation 40 (3-4): 53-70. doi:10.1300/J076v40n03_03.

Dukic, D., McDonald, B. B., and R. Spaaij. 2017. "Being Able to Play: Experiences of Social Inclusion and Exclusion within a Football Team of People Seeking Asylum." Social Inclusion 5 (2): 101-110. doi:10.17645/si.v5i2.892.

Ekholm, D. 2016. "Sport as a Means of Responding to Social Problems: Rationales of Government, Welfare, and Social Change." PhD diss., Linköping University.

Ekholm, D., and M. Dahlstedt. 2017. "Football for Inclusion: Examining the Pedagogic Rationalities and the Technologies of Solidarity of a Sports-Based Intervention in Sweden." Social Inclusion 5 (2): 232-240. doi:10.17645/si.v5i2.839.

Fader, J. 2008. "Inside and Out: Community Reentry, Continuity and Change Among FormerlyIncarcerated Urban Youth." PhD diss., University of Pennsylvania.

Fritzén, L. 2001. ” Förarintyg på sjön: Om pedagogikens möjligheter på särskilda ungdomshem.” In Kommunikativ Pedagogik och Särskilda Ungdomshem, edited by P. Gerrevall and H. Jenner, 31-43. Stockholm, Sweden: Statens institutionsstyrelse.

Gerrevall, P., and H. Jenner, eds. 2001. Kommunikativ Pedagogik Och Särskilda Ungdomshem. Stockholm, Sweden: Statens institutionsstyrelse.

Haudenhuyse, R. P., M. Theeboom, and F. Coalter. 2012. “The Potential of Sports-based Social Interventions for Vulnerable Youth: Implications for Sport Coaches and Youth Workers." Journal of Youth Studies 15 (4): 437-454. doi:10.1080/13676261.2012.663895.

Haudenhuyse, R. P., M. Theeboom, and E. A. Skille. 2014. “Towards Understanding the Potential of Sports-based Practices for Socially Vulnerable Youth." Sport in Society 17 (2): 139-156. doi:10.10 80/17430437.2013.790897.

Hertting, K. 2010. "Leading with Pedagogical Tact: A Challenge in Children's Sports in Sweden." Sport Science Review 19 (1-2): 127-147. doi:10.2478/v10237-011-0008-9.

Hugo, M. 2013. Meningsfullt la"Rande i Skolverksamheten På Sa"Rskilda Ungdomshem. Stockholm, Sweden: Statens Institutionsstyrelse.

Jenner, H. 2004. Motivation Och Motivationsarbete i Skola Och Behandling. Stockholm, Sweden: Myndigheten för skolutveckling.

Kelly, L. 2013. "Sports-based Interventions and the Local Governance of Youth Crime and Antisocial Behavior." Journal of Sport and Social Issues 37 (3): 261-283. doi:10.1177/0193723512467193.

Kilgore, D., and S. Meade. 2004. 'Look What Boot Camp's Done for Me:' Teaching and Learning at Lakeview Academy." Journal of Correctional Education 55 (2): 170-185.

Mahoney, J. L., and H. Stattin. 2000. "Leisure Activities and Adolescents' Antisocial Behavior: The Role of Structure and Social Context." Journal of Adolescence 23 (2): 113-127. doi:10.1006/ jado.2000.0302.

Meek, R. 2012. The role of sport in promoting desistance from crime. Southampton: University of Southhampton/2nd Chance Project.

Meek, R. 2014. Sport in Prison: Exploring the Role of Physical Activity in Correctional Settings. London, UK: Routledge.

Meek, R., and G. Lewis. 2014. "The Impact of a Sports Initiative for Young Men in Prison: Staff and Participant Perspectives." Journal of Sport and Social Issues 1038 (2): 95-123. doi:10.1177/0193723512472896.

Muncie, J. 2008. “The Punitive Turn in Juvenile Justice: Cultures of Control and Rights Compliance in Western Europe and the USA." Youth Justice 8 (2): 107-121. doi:10.1177/1473225408091372.

Nichols, G. 2007. Sport and Crime Reduction: The Role of Sports in Tackling Youth Crime. London, UK: Routledge. 
Norman, M. 2015. "Sport and Physical Recreation in Canadian Federal Prisons: An Exploratory Study of Carceral Physical Culture.” PhD diss., University of Toronto.

Parker, A., R. Meek, and G. Lewis. 2014. "Sport in a Youth Prison: Male Young Offenders' Experiences of a Sporting Intervention." Journal of Youth Studies 17 (3): 381-396. doi:10.1080/13676261.2013 .830699 .

Spruit, A., E. van Vugt, C. van der Put, T. van der Stouwe, and G. Stams. 2016. "Sports Participation and Juvenile Delinquency: A Meta-Analytic Review.” Journal of Youth and Adolescence 45 (4): 655-671. doi:10.1007/s10964-015-0389-7.

Statens institutionsstyrelse. 2014. SiS etiska riktlinjer. Stockholm, Sweden: Statens institutionsstyrelse.

Sugden, J., and A. Yiannakis. 1982. "Sport and Juvenile Delinquency: A Theoretical Base." Journal of Sport and Social Issues 6 (1): 22-30. doi:10.1177/019372358200600103.

Swartz, S. 2011. 'Going Deep' and 'Giving Back': Strategies for Exceeding Ethical Expectations When Researching Amongst Vulnerable Youth." Qualitative Research 11 (1): 47-68. doi:10.1177/1468794110385885.

Swedish Research Council. 2002. Forskningsetiska Principer Inom Humanistisk-Samhällsvetenskaplig Forskning. Stockholm, Sweden: Swedish Research Council.

Van Hout, M. C., and D. Phelan. 2014. "A Grounded Theory of Fitness Training and Sports Participation in Young Adult Male Offenders." Journal of Sport and Social Issues 38 (2): 124-147. doi:10.1177/0193723513520012.

Van Manen, M. 1990. Researching Lived Experience: Human Science for an Action Sensitive Pedagogy. Albany, NY: SUNY Press.

Van Manen, M. 2015. Pedagogical Tact: Knowing What to Do When You Don't Know What to Do. Walnut Creek, CA: Left Coast Press.

Van Manen, M. 2016. Phenomenology of Practice: Meaning-Giving Methods in Phenomenological Research and Writing. New York, NY: Routledge.

Williams, D. J., W. B. Strean, and E. G. Bengoechea. 2002. "Understanding Recreation and Sport as a Rehabilitative Tool within Juvenile Justice Programs." Juvenile and Family Court Journal 53 (2): 31-41. doi:10.1111/j.1755-6988.2002.tb00060.x. 